\section{Patienten-Selbsttest für Harnwegsinfekte}

— Seit Kurzem ist in Apotheken ein neu entwickelter Patienten-Selbsttest zur Früherkennung von Harnwegsinfektionen erhältlich. Unnötige Arztbesuche oder Antibiotika-Behandlungen könnten damit vermieden werden.

Die Testkarte wird in einen Becher mit Urin (Plastikbecher wird mitgeliefert) gestellt. Nach fünf Minuten kann man auf zwei Farbskalen ablesen, ob Nitrit und/oder vermehrt Leukozyten enthalten sind. Das Ergebnis bleibt 24 Stunden lang stabil. Die Sensitivität des in Deutschland unter dem Namen „punctomed Urin-Test“ vertriebenen Tests bezifferte Dr. Thomas Kaltenbach vom Unternehmen Swiss Medical Solution AG aus Büron in der Schweiz mit 93,3\%, die Spezifität mit 78\%. „Dies entspricht ziemlich genau den Ergebnissen professioneller Teststreifen“, so Kaltenbach. Allerdings seien die Fehlermöglichkeiten bei der Bestimmung wesentlich geringer.

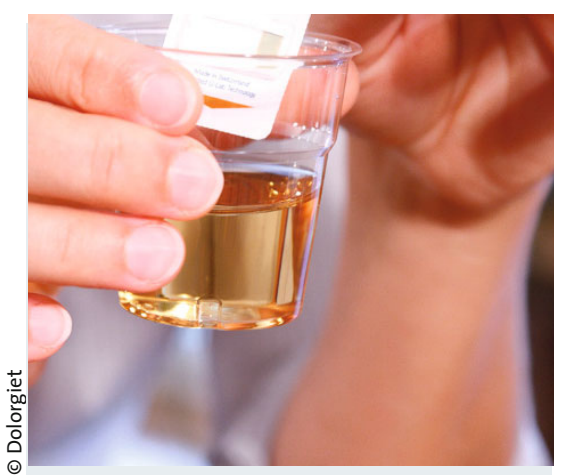

Der Selbsttest bietet dem Patienten ersten Anhalt für den Harnwegsinfekt

Zum Farbumschlag kommt es bei Nitritkonzentrationen von 0,05 bis $0,1 \mathrm{mg} / \mathrm{dl}$ und bei 10-20 Leukozyten/ $\mu$ l Urin.

Nach Meinung von Prof. Dr. Dirk Watermann von der Universitätsfrauenklinik in Freiburg kann der Test Frauen helfen, eine Reizung der Blase von einem manifesten
Infekt zu unterscheiden. Dies gilt besonders für jene $5-10 \%$ der Frauen, die unter rezidivierenden Harnwegsinfekten leiden. $\mathrm{Zu}$ viele Frauen mit unkomplizierten HWI erhielten Antibiotika, sagte Dr. Michael Kresken von der Paul-Ehrlich-Gesellschaft für Chemotherapie. Er wies auf die stetige Zunahme von Escherichia-coli-Resistenzen hin. Zugleich sei in den nächsten Jahren mit nur wenigen neuen Wirkstoffen zu rechnen. In etwa 40\% aller HWI-Verdachtsfälle sei die Antibiotika-Einnahme unnötig. Kresken wörtlich: „Antibiotika könnten eingespart werden, wenn zunächst nur solche Patientinnen antibiotisch behandelt würden, bei denen Nitrit und vermehrt Leukozyten im Urin nachweisbar sind." Ein Test soll nach Angaben des Unternehmens 7 bis 8 Euro kosten.

TM

Pressekonferenz „punctomed - der neue Urin-Selbsttest. Selbst sicher auf Harnwegsinfekte testen und Antibiotikaeinsatz verringern“, Frankfurt am Main, 01. Oktober 2009; Veranstalter: Dolorgiet

\title{
Kombination Dutasterid/Tamsulosin verbessert die Prognose bei BPH
}

\begin{abstract}
- Wie die neuen 4-Jahres-Ergebnisse der CombAT (Combination of Avodart and Tamsulosin)-Studie zeigen, können Patienten mit moderater bis schwerer benigner Prostatahyperplasie (BPH) und relevantem Progressionsrisiko durch eine langfristige Kombinationstherapie mit dem $\alpha$-Blocker Tamsulosin (o,4 mg/d) und dem $5 \alpha$-Reduktase-Inhibitor (5-ARI) Dutasterid (0,5 mg/d)
\end{abstract}

vor einer raschen Progression der Erkrankung geschützt werden, berichtete PD Dr. Stephan Madersbacher, Wien. In der Studie erhielten 4.844 BPH-Patienten (IPSS [International Prostate Symptom Score] $\geq 12$, durchschnittliches Prostatavolumen $55 \mathrm{ml}$ und Serum-PSA von 1,5 bis $20 \mathrm{ng} / \mathrm{ml}$ ) entweder die Kombinations- oder eine der beiden Monotherapien.

\section{www.laenger-geniessen.de - ein neues Portal für Ejaculatio-praecox-Betroffene}

— Männern und Frauen trauen sich oft nicht, über Funktionsstörungen zu sprechen. „Paaren fällt es leicht, sich über schöne gemeinsame sexuelle Erfahrung zu unterhalten. Läuft jedoch etwas schief, wird das Thema zum Tabu“, erklärt Dr. UIrike Brandenburg, Sexualtherapeutin aus Aachen. Eine Aussprache in Gang zu brin- gen und der Weg zum Arzt ist aber meist unumgänglich. www.laenger-geniessen.de kann als erste Anlaufstelle dienen, um sich umfangreich über den vorzeitigen Samenerguss zu informiern und Mut zu sammeln, sich jemandem anzuvertrauen.

Nach Informationen von Janssen-Cilag
Gegenüber den Monotherapien führte die Kombination zu einer stärkeren Symptomlinderung. „Nur durch eine konsequente Dauertherapie mit Dutasterid plus Tamsulosin kann im Gegensatz zur Tamsulosin-Monotherapie die Symptomlinderung aufrecht erhalten werden", so Madersbacher. Bei steigendem Prostatavolumen nahm der therapeutische Nutzen der Kombinationstherapie gegenüber dem $\alpha$-Blocker hinsichtlich der Symptomatik stetig zu. Die Gesamtinzidienz für akuten Harnverhalt oder BPH-bedingte Operationen betrug nach 4-jähriger Therapie $4,2 \%$ im Kombinationsarm vs. $5,2 \%$ unter Dutasterid- bzw. 11,9\% unter Tamsulosin-Monotherapie (jeweils $p<0,0001$ ). Die Kombinationstherapie hat laut Madersbacher das Komplikationsrisiko um 19,6\% gegenüber dem 5-ARI und um 65,8\% gegenüber dem $\alpha$-Blocker reduziert.

aam

Pressegespräch „4-Jahres-Daten der CombAT-Studie: Akuter Harnverhalt und OP bei der BPH müssen nicht sein", München, 12. November 2009; Veranstalter: GlaxoSmithKline 